\title{
UNIVERSITYOF
}

FORWARD

THINKING

WESTMINSTER用

WestminsterResearch

http://www.westminster.ac.uk/westminsterresearch

Cyborg Activism: Exploring the reconfigurations of democratic subjectivity in Anonymous

Asenbaum, $\mathrm{H}$.

This is a copy of the accepted author manuscript of the following article: Asenbaum, $\mathrm{H}$. (2017) Cyborg Activism: Exploring the reconfigurations of democratic subjectivity in Anonymous, New Media \& Society, doi:10.1177/1461444817699994. The final definitive version is available from the publisher Sage at:

https://dx.doi.org/10.1177/14614448817699994

(C) The Author(s) 2017

The WestminsterResearch online digital archive at the University of Westminster aims to make the research output of the University available to a wider audience. Copyright and Moral Rights remain with the authors and/or copyright owners.

Whilst further distribution of specific materials from within this archive is forbidden, you may freely distribute the URL of WestminsterResearch: ((http://westminsterresearch.wmin.ac.uk/)).

In case of abuse or copyright appearing without permission e-mail repository@westminster.ac.uk 


\section{Cyborg Activism: Exploring the reconfigurations of democratic subjectivity in}

\section{Anonymous}

The rapid change that society is currently experiencing is accompanied, challenged and promoted by novel forms of activism that increasingly employ online communication. In order to make sense of these new phenomena, theoretical conceptualisations like the notion of connective action by Bennett and Segerberg (2013) look at the social movement, network or swarm as a whole and thus focus on the macro-level of democratic subjectivity. This article proposes a different perspective, starting the analysis from the micro-level of democratic subjectivity. Here, we find the democratic subject, the individual in his or her role as an activist. Only if we start from the individual democratic subject can we comprehend new forms of political digital engagement, which I call cyborg activism.

Defining the individual democratic subject in societies of the Information Age as cyborg draws attention to the continuous process of reconfiguration of modern binaries, which disrupts modern thought, the way we are taught to perceive reality. These reconfigurations start at the micro-level of democratic subjectivity and reassemble the individual as a fusion of human/machine, organic/digital, which sets in motion a process of reconfiguration at multiple levels of society, with political activism being one of them.

The online collectivity Anonymous appears to be a prototype of such a new form of activism, as its activity comprises political engagement, both online and offline. 
Moreover, Anonymous makes use of the technologically mediated opportunities of visibility and invisibility, both concealing and creating digital identities. Exploring the history, organisational structures and political claims of Anonymous contributes to understanding new activist formations. As Uitermark (2016: 12) states: “Attempting to understand Anonymous requires a rethinking of what movements are and how we can understand them. New movements generally challenge old frameworks and therefore prompt the reconsideration and reformulation of established theories and vocabularies."

A review of the multi-facetted, interdisciplinary literature concerning Anonymous that has emerged in the last seven years makes clear how the focus on the reconfiguration of binaries lies at the heart of this subject of study. Ravetto-Biagioli (2013) claims Anonymous "upsets dichotomies that are fundamental to traditional political thought and practice, like identification and anonymity, performing identity and persistent identity, liberation and control, dissent and accountability, privacy and piracy" (180). Cambre (2014: 304) identifies three themes in her digital ethnographic study of the use of masking in visuals circulated by Anonymous: mask/face, community/anonymity and surveillance/freedom. Goode (2015) structures his discussion of the political ethos of Anonymous along four points of tension: nihilism/idealism, utopianism/dystopianism, individualism/collectivism and positive/negative liberty. And Fuchs' (2013; 2014) discourse and content analyses locate Anonymous in an ideological spectrum between liberalism and socialism. 
This article pursues three goals: first, it develops the theoretical concept of cyborg activism and illustrates it by drawing on empirical findings and theoretical discussions regarding Anonymous. Second, it presents the first extensive literature review on Anonymous, thus connecting hitherto disparate discussions and putting the work of diverse researchers from multiple disciplines into dialogue. And third, by doing so, it reconsiders and challenges the established narrative regarding Anonymous.

\section{What is cyborg activism?}

In order to develop the concept of cyborg activism, a look at current debates about digital activism renders a helpful foundation. Soon after the simultaneous emergence of the Arab Spring, the Occupy movement and the Indignados, three influential books were published. Manuel Castells' (2012) Networks of Outrage and Hope, Lance Bennett and Alexandra Segerberg's (2013) The Logic of Connective Action, and Paolo Gerbaudo's (2012) Tweets and the Streets developed new concepts of digital activism. Castells' networked social movements, which he refers to as "a new species of social movements" (p. 15) contest the ruling order in new hybrid digital/physical spaces of autonomy. Networked social movements are characterized by their horizontal and leaderless organisation. Castells focuses on the emotive aspects of such movements, which generate spaces of outrage, enthusiasm and hope. Moreover, networked movements are nonprogrammatic and promote diverse causes of social change. This last point of Castells is the central theme of Bennett and Segerberg's connective action. By generating inclusive 
action frames, like Occupy's "We are the 99\%", digital activists allow for the expression of multiple political issues and rooted in diverse ideologies. Just like Castells, digital activists' connective action promotes contentious politics that overcome hierarchical internal structures and allows for individuality and autonomy.

Both concepts of networked social movements and connective action have been facing criticism of technodeterminism and cyberoptimism as they primarily focus on positive aspects of digital activism. This perspective draws a picture of digital activism as horizontally structured and diverse in content. Gerbaudo's work aims at overcoming this one-sided perception with the concept of choreographic leadership. While digital activists promote and adhere to an ideology and self-perception of horizontality, spontaneity, and individuality, clear patterns of "soft leadership" by "reluctant leaders" emerge as social media is used to coordinate collective action. Like Castells, Gerbaudo stresses the emotive quality of hybrid digital/physical spaces as a new sense of togetherness emerges.

The concept of cyborg activism builds on the lessons learnt from the authors discussed above, by focusing on its three main themes: (1) horizontality, (2) emotion, and (3) diversity of content. Gerbaudo and Castells take an important step away from technodeterminism by focusing on emotions as a human or social factor vis-à-vis technology. Cyborg activism further pursues this path by starting from the reconfiguration of the activist's material body on the micro-level of democratic 
subjectivity.

To develop novel understandings of digital activism, I pick up another strand of theory: Conceptions of the cyborg define the individual, and thus the democratic subject, as a hybrid of biology and technology. It focuses on modern binaries and their reconfigurations through technology. This perspective makes the perception of both elements of the respective binary inevitable and thus prevents one-sided perceptions. The three main themes of digital activism identified in the discussion above thus appear as the reconfigured binaries of (1) equality/hierarchy, (2) reason/emotion, and (3) nihilism/idealism. Before discussing the reconfiguration of these binaries, which lie at the heart of cyborg activism, in more detail, I will lay its foundation by briefly discussing the concept of the cyborg and democratic subjectivity in cyborg society.

The original concept of the cyborg, which reflects the entanglement of human and machine, nature and technology, emerging in feminist theory, science and technology studies, and science fiction, described the incorporation of robotic limbs and organs into the human body, resulting in humans enhanced by artificial intelligence. With the use of cardiac pacemakers, robotic prostheses, and plastic surgery on the rise, cyborgs in their original interpretation do not now seem so implausible. More recent conceptualisations of the cyborg, however, argue that the last decade is characterised by everyday cyborgization through the employment of digital communication devices. We have let these electronic devices become an indispensable part of our selves. Without 
smartphones, we feel naked - unable to access stored knowledge and cut off from social interaction, we feel inhibited, almost as if we are missing a limb. The transformation from human to cyborg does not, however, take place at the level of human/machine only, as in the original version, but also entails fusion of organic/digital. On the one hand, cyborgs consist of human bodies closely allied with hardware like smartphones, smartwatches, and headsets. On the other hand, they are made up of multiple digital representations through which they communicate online.

This change in communication through new limbs, which have grown on us in just a few years, and through our new digital selves disrupts the modern logic conceptualising society in binary terms. These binaries are not overcome altogether, but they are reconfigured resulting in a reorganisation of the individual, society and activism as part of radical democratic politics. To lay the ground for the concept of cyborg activism, democratic subjectivity in cyborg society will be discussed as the reconfiguration of nature/technology at the micro-level, identity/anonymity at the meso-level, and public/private at the macro-level.

At the micro-level of democratic subjectivity lies the reconfiguration of nature and technology with digital communication devices pervading not only work and social relations, but even intimate sexual relations through dating sites, online pornography, and video chat ("cam sex"). Heart rates, blood flows and orgasms are mediated by digital performances. The alliance of flesh and technology, mind and software allows not only 
for communication with others but also for an intimate relation between the human and the electronic device itself. This relationship is characterised by an odd dualism: The technological device is on the one hand fetishized as an object of desire and material possession and on the other hand its intuitive use naturalises it and lets it go unnoticed as it is incorporated into the social and biological processes of everyday life.

This reconfiguration of human/machine triggers the reconfiguration of a multitude of other binaries. In order for the individual cyborg (micro-level) to communicate to others (macro-level), he or she needs a digital persona as a meso-level medium. This digital persona emerges as a product of the electronic reconfiguration of identity/anonymity. Online communication mixes anonymity with identity to various degrees from nicknames in chats, to avatars in online gaming, and social media profiles. Elements of identity within digital personae serve the identification of conversation partners (not, however, their legal identity). Elements of anonymity render digital personae multiple, incoherent, contingent, and ephemeral. Boundaries of race, class, gender, sexuality, age, social status etc. become more porous as individuals perform alternative aspects of their selves in the digital realm between fiction and reality (cf. Kafai et al., 2007; Zhao et al., 2008). The share of anonymity in this combination is decreasing in the era of facebook and current trends towards identification and surveillance. Open source and hacktivist movements strive to preserve and create new spaces of anonymity and identity play.

These digital personae permeate the border between the public and the private, which 
represents the shift at the macro-level of democratic subjectivity. Online spaces are inhabited by digital personae whose physical bodies are often located in private social settings. Zealously campaigning or articulately discussing political matters, democratic subjects sit on their couch in their underwear or lie in bed snuggled up with their sexual partners. The emotions triggered by public debate are dealt with in the private sphere (cf. Vivienne and Burgess, 2012). While digital communication creates new publics, cyborg citizens are keen on protecting their privacy. Privacy is maintained in public through certain degrees of anonymity, partly eroding the border between privacy and publicity. These reconfigurations of nature/technology, identity/anonymity and public/private at the micro-, meso- and macro-level of democratic subjectivity in cyborg society build the foundation of a new kind of activism. Cyborg activism is defined by the continuous process of reconfiguration of the modern binaries of equality/hierarchy, reason/emotion, and nihilism/idealism.

First, cyborg activist formations are characterised by leaving behind clear, fixed hierarchies and at the same time failing to realise full equality (cf. Gerbaudo, 2012: 134ff). Rather, hierarchies in cyborg activist formations prove to be as contingent, volatile, and ephemeral as digital personae themselves. In contrast with traditional social movements, this results in an amorphous and fluid nature. This does not mean overcoming leader/follower relations, but infusing them with greater contingency.

Second, the technological mediation of the social allows for bringing new emotive 
qualities into the realm of rational politics (cf. Castells 2012; Gerbaudo, 2012: 159ff). As the private pervades public spaces, the modern separation of rationality, objectivity and cool-headed politics on the one hand and emotion, passion and affect on the other, is reconfigured. Cyborg activists combine their political reasoning with the hunt for laughter and joy. Vigorously seeking schadenfreude, some cyborg activist groups construct threatening vigilante identities and engage in political trolling of sex offenders, animal abusers or racists. Cyborg activists zealously campaign for their political causes using a means of digital carnivalesque performances to invoke fear, happiness, pain, and anger in their allies and opponents.

And third, the political claims and contents promoted by cyborg activist formations are characterised by an odd integration of nihilism and idealism. This combines nihilist antisystem resentments, anti- or post-political attitudes and disenchantment with politics with idealist visions and heterogeneous political ideas. Nihilism as the denial of the political paradoxically opens the door for the inclusion of a great diversity of thought within one activist formation (cf. Bennett and Segerberg, 2013; Castells, 2012) of liberalism/socialism, representative democracy/participatory democracy, racism/humanism etc.

Now, one might object: But are these binaries really new? Have social movements not always exhibited both hierarchical and egalitarian elements, has their political engagement not always consisted of both reasoned strategy and emotional fervour, and 
have they not always promoted diverse content? The answer is: yes and no! Cyborg activism represents both a new theoretical perspective that draws attention to phenomena that already exist and the observation of an actual shift in activism. The actual shift is brought about by the reconfiguration of nature/technology and the consecutive reconfigurations, as argued above. Social movements have exhibited both leadership and egalitarian relations, though these used to be much more fixed and stable. Once a leader had accumulated reputation and trust, he or she was likely to stay in that position. As will be illustrated by Anonymous, as digital identities shift and expire, so do positions of leadership. Likewise, emotions were always an integral part of social movements. The quality and kind of emotions, however, appear to have changed through their electronic mediation. Experiencing the joy of community in physical solitude or experiencing the satisfaction of others agreeing to one's political argument through 1000 electronic likes instead of some smiles and nods in a face-to-face gathering brings new qualities to activist engagement. Despite the power of online "bubbles", new electronic settings increase the probability of unlike-minded activists engaging in discussions, compared to offline activist gatherings. The resulting outbursts of aversion are thus, in part, owed to new technological structures. And while traditional social movements always promoted diverse content in comparison with NGOs, cyborg activist formations prove to be even more heterogeneous because of the inclusive effects and low entrance costs through digital media. 


\section{Anonymous in interdisciplinary perspective}

When an entirely new phenomenon emerges, it is impossible to locate it in only one academic field. This explains the need for interdisciplinary research. Accordingly, while it might be expected that Anonymous could be located in communication and media studies, it reaches far beyond these disciplines. The academic accounts discussed here are from Media and Communication Studies (10) ${ }^{1}$, Anthropology (6), Political Science (6), Sociology (6), Cultural Studies (6), Technology and Computer Sciences (5), Law (3), Management Studies (1), Philosophy (1) and Security Studies (1). Each of the disciplines provides assets for looking at certain aspects of Anonymous as a research subject. The literature review presented here draws on 47 journal articles, monographs and conference papers in English language. The academic work on Anonymous proves rich in primary data generated by methods as diverse as participant observations, image interpretations, ethnographies, and discourse, content, and frame analyses. Besides methodological diversity, the fascination with Anonymous as research subject has also inspired theoretical innovations drawing on the work of Foucault, Castells, Luhmann, Bennett, Marx, Gramsci, Negri and Hardt, Mouffe, Bloch, and Deleuze, to name a few.

The observation of the central position of Gabriella Coleman in the study of Anonymous, as mentioned by many authors (Potter, 2015: 4; Klein, 2015: 5; Dunn Cavelty and Jaeger, 2015: 177; Jarvis, 2014: 1), proves entirely true. Coleman's ethnographic observations extending over years and her numerous publications (Coleman, 2011a, 2011b, 2012, 
$2013,2014)$ laid the groundwork for many other scholars. While a lot of insight is owed to the valuable work of Coleman, her central position in the field also leads to the establishment of a certain narrative of Anonymous. Her main thesis, stating that Anonymous transformed from an apolitical group pursuing mischief to a political actor, has been cited and re-cited (Bodó, 2014: 2; Dobusch and Schoeneborn, 2015: 11; Gekker, 2012: 183; Hai-Jew, 2013: 64; McDonald, 2015: 972; Sauter, 2013: 990). Below I will offer an alternative reading. What is important for now is that, ironically, Coleman's work itself has become a meme ${ }^{2}$. This centrality becomes evident when looking at the network of who cites whom in the works discussed in this review (see Figure 1). Coleman is cited in $84 \%$ of the works reviewed here. The authors cited the second most are only cited by $11 \%$. For $41 \%$, Coleman is the only academic source. Moreover, authors rarely cite each other, which means that a lot of valuable insights are not passed on. This is mostly due to the fact that events around Anonymous unravelled rapidly and scholars worked simultaneously. Thus, this review aims to draw attention to the abundance of scholarly work on the subject and to bring it into dialogue.

Figure 1: Who cites whom in literature on Anonymous 


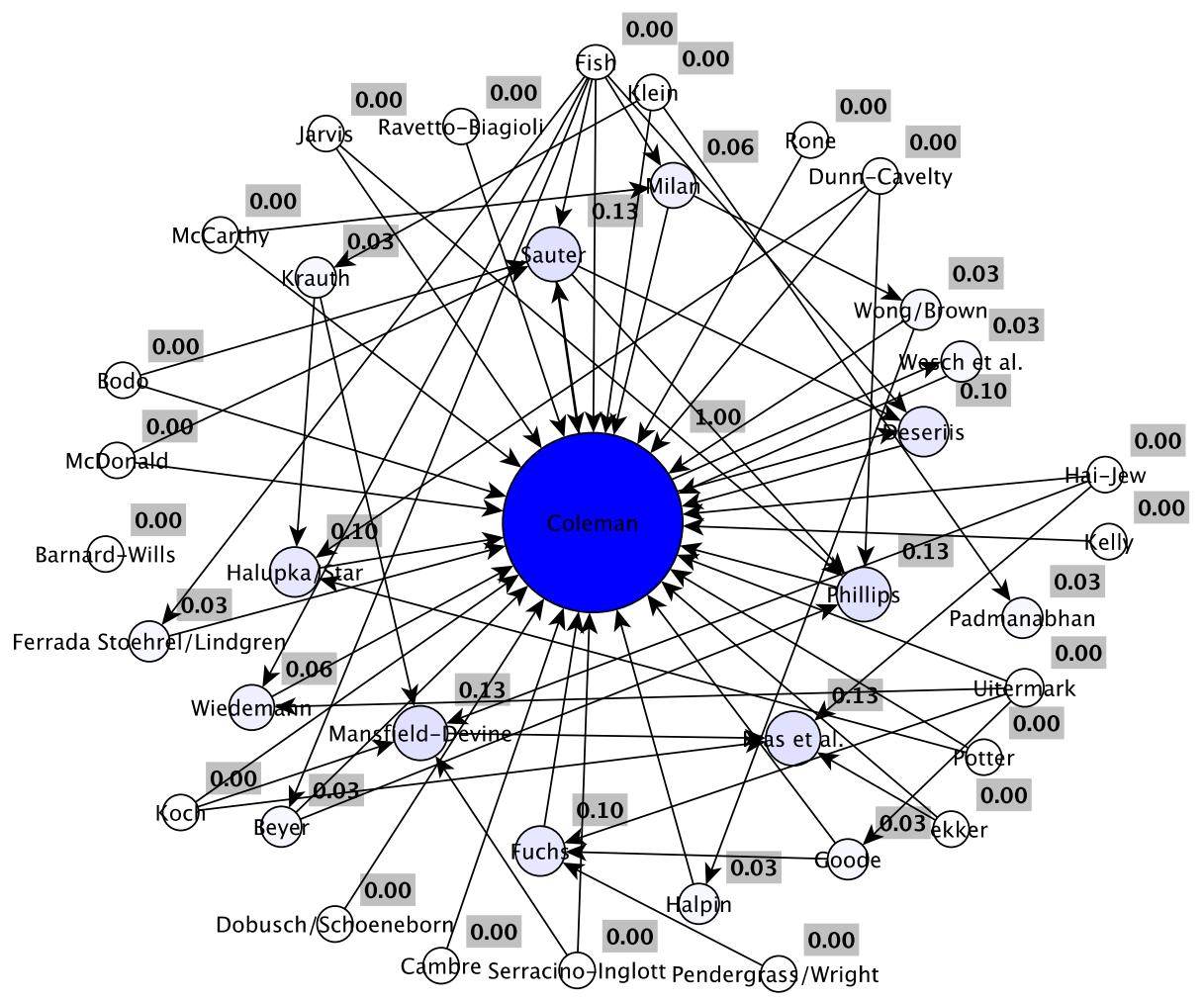

In this diverse complex of literature Anonymous has been described as a vigilant movement (Serracino-Inglott, 2013), a fluid organisation (Dobusch and Schoeneborn, 2015), a meme complex (Jarvis 2014), a maze generating mazes (Coleman 2014), a hybrid between network and swarm (Wiedemann, 2014), a cloud (Milan, 2013b), Ebandits (Wong and Brown, 2013), cybercriminals (Kelly, 2012), a trolling identity (Phillips, 2012), an improper name (Deseriis, 2013) and an on-going flash mob (HayJew, 2013). In what follows, I will add another term and describe Anonymous as a cyborg activist formation consisting of the reconfiguration of equality/hierarchy, reason/emotion, and nihilism/idealism. 


\section{The reconfiguration of equality/hierarchy in Anonymous}

The reconfiguration of equality/hierarchy as element of cyborg activism can be detected on two levels in the literature on Anonymous: First, a transformative shift between equality/hierarchy can be identified in Anonymous' historic place of origin, 4chan. And second, these reconfigurations are reflected in the organisational structures of Anonymous.

\section{The paradox of equality and hierarchy in Anonymous' origins}

Quite a lot of attention in the literature on Anonymous is given to its formation process on the image board, 4chan, and its sub-board, $/ b /$, starting in 2003. Many scholars claim that the interface of 4 chan had a deep impact on social interaction within Anonymous. These arguments are sometimes reminiscent of 1990s technodeterminism: "For Anonymous, there is a sort of leader that is the infrastructure" (Wiedemann, 2014: 319). However, the claim that technical protocol influences the social formation within that protocol (Gekker, 2012 citing Galoway) is convincing and empirically well founded. Beyer (2014a) shows in an extensive case study that compares four online spaces that sites like 4chan contribute to social mobilisation by structurally providing a high level of anonymity and a low level of formal regulation.

Structural anonymity, as a key feature on 4chan, is said to have strongly affected the evolution of Anonymous. The alias "anonymous", given to everyone interacting on this 
site, became the moniker for the emerging collective actor. The significance of anonymity becomes evident when comparing Anonymous to of (primarily) offline social movements. While social hierarchies are evident in physical activist gatherings, in online communication, the lack of markers of social status has inclusive effects (Wiedemann, 2014: 320). By hiding identities, 4chan aims to establish meritocratic principles.

The ephemerality of the site, letting every post expire as new posts appear, can be interpreted in terms of a critique of digital archiving and monitoring. McDonald (2015: 979) sees 4chan and Anonymous as antithesis to the Facebook culture of naming, liking and tagging, which connects value to the persona, not the content, and creates an archive easily abused for surveillance (cf. Cambre, 2014: 305). This leads Halpin to interpret Anonymous as an anti-capitalist project: "Anonymous [...] is an ontological shift on the terrain of identity at the very moment that identity has become the highest form of selection and exploitation in cognitive capitalism, the first glimpse of life without identity on the Internet" (Halpin, 2012: 19). Following this argument, 4chan is characterised by equality enabled by anonymity.

Other authors, however, blame anonymity for flaming and derogatory speech on 4chan, which specifically addresses marginalised social groups (e.g., Ravetto-Biagioli, 2013: 184). This replicates and amplifies social hierarchies in the new participatory space (Uitmark, 2016: 5). "Conceived initially as forum for anime, [4chan] came to specialize in adolescent, gross-out' content, pornography, and politically incorrect humor. It became 
a carnivalesque celebration of free speech through the transgression of conventions and taboos around depictions of violence and sex" (Goode, 2015: 76). Pejorative demeanour is sometimes justified in literature referring to a political conviction of free speech as the highest social principle (cf. Potter, 2015: 9). The term "fag" is ubiquitous on 4chan. New users are called "newfags", British users "britfags", politically active ones "moralfags", homosexuals "gayfags", and so on.

So the question arises, whether anonymity within Anonymous is generating equality or re-affirming social hierarchies. I contend that as cyborg activist formation Anonymous does both. Phillips differentiates: "Depending on the context, ,-fag' can function as a homophobic slur, term of endearment, or neutral mode of self-identification" (Phillips, 2012: 498). To understand this paradox, it is necessary to focus on the function of derogatory speech on digital spaces inhabited by Anonymous. One function is obviously to insult outsiders and create a barrier for participation. The other function, however, consists of building a community, a place of belonging. Exclusion and inclusion are interrelated. Typical 4chan users are "nerds" and "geeks" (Coleman, 2011a) who often are victims of bullying and generally find little appreciation by society. On 4chan, they create a counter public (Fraser, 1990) in opposition to mainstream culture. Defending this social space aggressively is one side of the coin; the other consists of a community of equals (Wesch, 2012: 98). All equally acknowledge their peripheral role in society and reflect the experienced personal devaluation in their self-address. In addition to this 
"therapeutic" function, the self-identification as "faggot" expresses solidarity with other marginalised groups. Thus, paradoxically, pejorative language also (but not exclusively!) serves the function of promoting equality: "the mask symbolised the universally shared feeling of exclusion, which applied to everyone with no regard to individual differences" (Bodó, 2014: 3; cf. Halpin, 2012: 26). So derogatory speech on 4chan serves both inclusion and exclusion; it promotes equality and solidarity, on the one hand, and affirms hierarchies, on the other.

\section{The dialectic of equality and hierarchy in Anonymous' structures}

These reconfigurations of equality/hierarchy that paradoxically promote both inclusive and exclusive tendencies through the structural settings of Anonymous' place of origin are also reflected in the organisational structures of Anonymous emerging thereafter.

The literature concerned with organisational structures and decision-making procedures in Anonymous gives insight into the apparent paradox of equality and hierarchy within Anonymous. This paradox is also reflected in the literature, which appears divided (cf. Krauth, 2012: 29). While some authors describe Anonymous' internal structure as direct democratic community of equals (Barnard-Wills, 2011: 20; Halupka and Star, 2011; Potter, 2015: 1; Wong and Brown, 2013: 1024), others paint a contrary picture of internal hierarchy, control and command (Hai-Jew, 2013: 76; Kelly, 2012: 1682; Koch, 2014: 464; Krauth, 2012: 28; Mansfield-Devine, 2011: 7) 
In principle, participation in Anonymous is open for everyone. The symbols of Anonymous, like the Guy Fawkes mask and the headless figure with a question mark, are available for anyone to use. Messages in the name of Anonymous can be spread via social media by anyone, as their originators are unknown - mostly even to each other. The participation in and initiation of Anonymous' campaigns is unrestricted. Thus, temporary positions of leadership are accessible, while the decentralised structure makes it impossible to establish leadership permanently (Coleman, 2014: 393). However, a study by Dobusch and Schoeneborn (2015) indicates that hierarchies exist within Anonymous. Their identity-claim analysis focuses on announcements in the name of Anonymous that later were identified as "unauthentic" by some Anons. Thus, its participants publicly negotiate Anonymous - a process in which the claims of some appear superior to those of others. So how is power distributed in Anonymous?

Some authors suggest influence in Anonymous correlates with technical skills (Coleman, 2013; Uitmark, 2016). Thus, a look at Anonymous' tactics can explain internal hierarchies. Anonymous consists of thousands of individuals that partially gather in groups divided along local issues, hacking abilities or political motivations. Activists partially set up their own communicative infrastructure made up of websites and internet Relay Chats (IRCs), and they partially rely on common social media. IRCs are used to organise attacks and campaigns. These typically employ four tactics (Klein, 2015: 9; for more tactics see Jarvis, 2014: 12ff). 
First, $D D o S$ attacks consist of website requests in such high numbers that servers cannot respond and websites become unavailable. In the terminology of Anonymous, this is framed as civil disobedience, replicating sit-ins and occupations in digital spaces. In an extensive study, Sauter $(2013 ; 2014)$ demonstrates how this tactic - employed by other digital activists before - was democratised by Anonymous by developing user friendly DDoS software, making it more accessible to less technically skilled users. Second, defacing consists of hacking a website and temporarily replacing it with another image and/or message, typically a political statement. Defacing and DDoS attacks demonstrate how Anonymous does not only create its own spaces but also occupies space of its opponents. Third, doxing means stealing someone's personal data and publishing them, a tactic typically employed against opponents like paedophiles, members of state agencies or even Anonymous activists themselves as means of expulsion (Dobusch and Schoeneborn, 2015). Fourth, mirroring is the tactic of uploading the same content like video messages etc. on multiple channels by multiple users in order to circumvent deletion by webpage providers (Fish, 2015).

This overview of tactics makes evident that different skills play an important role in Anonymous. While setting up IRCs, defacing and doxing require advanced technical skills, this is not the case for engaging on social media, DDoS attacks, and mirroring (Coleman, 2011a). So in spite of structural equality facilitated by anonymity, new hierarchies emerge. These do not only run along the lines of technical skills. The ability 
to speak in the language of a creative and exclusive subculture is also crucial: "participants must assert their membership status by extreme adherence to community practices and norms, while replacing individual identity markers with community symbols" (Beyer, 2014a: 46). Both acquiring technical skills and immerging into community culture are distinct pathways of ascending hierarchies in Anonymous.

In conclusion, Anonymous is, on the one hand, inclusive and decentralised, and on the other hand, pervaded with hierarchies. Krauth (2012) describes Anonymous as Portmanteaupia - a bifurcated space that combines centralisation and decentralisation. While hierarchies and leadership exist, they prove much more contingent and amorphous than in common social movements. Employing complexity theory, Uitmark (2016) analyses the power dynamics in Anonymous and their change over time. His study shows that despite equal access to participation in Anonymous, elite circles with higher technical skills form. While this constitutes clear hierarchies, elite circles prove as ephemeral as messages on 4chan; their members either lose interest, are arrested by police or lose control over the mass of Anonymous activists as the latter counter domination in acts of public discursive contestation. Thus, hierarchies in Anonymous keep appearing, disintegrating, and shifting.

\section{The reconfiguration of reason/emotion in Anonymous}

Research on Anonymous appears to be restricted by the binary of reason/emotion. Modern thought separates the realm of reason, which includes objective knowledge, 
science and cool-headed politics, from the realm of emotions, passion and affect. This division leads analysts to identify phenomena in only one of the two realms, overlooking their intersection. First, this is apparent in research on Anonymous in the construction of the narrative of its emergence, which is perceived as only emotional with irrational lulz ${ }^{3}$ as its objective. However, its more recent history is perceived as oriented towards rational politics, which overlooks its joyful, compassionate, and aggressive actions. Second, the discussion of the organisational structures of Anonymous as a network, swarm or cloud could benefit from a focus on emotions. Anonymous' politics of passion is driven by joy and anger.

\section{A political evolution}

The formation of a political actor from the 4chan subculture was triggered by interaction with the exterior world, growing from small scale individual trolling to larger scale raids and finally big "operations". Many scholars interpret the beginning of Anonymous as apolitical. They describe the transformation of a trolling group, seeking lulz into a political actor with moral values, picking up Coleman's (2011a; 2014) main thesis directly (Bodó, 2014: 2; Fuchs, 2014: 92; Gekker, 2012: 183; Hai-Jew, 2013: 64; McDonald, 2015: 972; Sauter, 2013: 990) or indirectly (Dobusch and Schoeneborn, 2015: 11; Halpin, 2012: 24; Sauter, 2014: 34f). This established narrative of Anonymous follows the modern binary that separates emotional lulz from rational politics.

By describing Anonymous as cyborg activist formation joining emotion and politics, I 
offer an alternative reading of Anonymous' evolution as political from the very beginning. One of the first actions, in which the moniker "Anonymous" was used, was the "Habbo Hotel Raid". In mid-2006, 4chan users coordinated trolling action to harass teenage users of the virtual Habbo Hotel. They created avatars of African appearance in black suits that blocked the entrance to the virtual pool. While this action can be read as apolitical trolling "for the lulz", it can also be interpreted as highly political: The creation of black avatars draws attention to the fact that this social minority is underrepresented on Habbo Hotel. The action was launched in response to rumours that moderators of Habbo Hotel discriminated against black users. As raiders were blocked, they charged moderators with racism. Moreover, the action employed civil disobedience in the form of blockage/occupation, typically employed by the US Civil Rights movement. In a follow up action on World of Warcraft, black avatars were marched to an auction as slaves (McDonald, 2015: 974). In this context the political motivation becomes evident. The next larger raid some months later was directed against white supremacist Hal Turner. These examples illustrate how emotional lulz that seek enjoyment, a feeling of power or revenge are inseparable from rational, political motivations.

While observing continuous political action from the emergence of Anonymous until today, I do not deny transformation. Instead of attributing an evolution from apolitical trolls to a social justice actor, I read the development of Anonymous in terms of visibility and political self-awareness. Sauter (2013: 990) observes a shift from insularity to 
visibility, and Dunn Cavelty and Jaeger (2015: 158) describe Anonymous' transformation from a meme creator to a visible meme itself. Anonymous' increasing visibility also contributed to its political self-awareness. So what changed is a focus from internal communication within to external communication. Of course, addressing the exterior provoked response. Growing literature on securitisation explains how Anonymous is a product of co-construction influenced by a hegemonic discourse on "cyberwar" and “cyberterrorism” (Barnard-Wills, 2011; Dunn Cavelty and Jaeger, 2015; Klein, 2015; Phillips, 2012; Ravetto-Biagioli, 2013).

Employing frame analysis, Klein (2015) shows how the image of Anonymous constructed by mainstream media and the self-perception of Anonymous diverge significantly. The analysis of 200 news articles about Anonymous reveals that in $58 \%$ of the cases Anonymous is portrayed as a "global threat" or a group of "malicious pranksters"; only $20 \%$ view them as a group of "legitimate activists". Examples of this co-construction of Anonymous are also found in the academic literature in the fields of law (Kelly, 2012; Padmanabhan, 2012) and technology studies (Pras et al., 2010), like the article by Mansfield-Devine (2011), which discusses whether Anonymous should be classified as a "serious threat or mere annoyance". Phillips (2012) describes how a FOX news report in 2007 was influential in co-constructing/securitising Anonymous. Anons laughed out loud as a TV audience of hundreds of thousands was informed that "hackers on steroids" threatened their online safety. This added to the motivation of taking 
coordinated actions to another level and attacking the Church of Scientology.

Most observers agree that entering into continuous confrontation with Scientology in 2008 marks the entry to a new phase in the history of Anonymous (Deseriis, 2013: 43; Dobusch and Schoeneborn, 2015: 11; Kelly, 2012: 1679; Sauter, 2013: 990; Uitmark, 2016: 6). Here the political motivation could still be questioned, as Scientology is not primarily perceived as a political actor, however, Anonymous' criticism of the church's suppression of free speech clearly expresses the main theme of the consolidating political agenda. It is important to note that at no point in its history was Anonymous a homogenous actor, but rather a loose network of several groups and individuals with various motivations (Beyer, 2014a: 43ff). While smaller scale trolling has transformed into vigilant justice action against paedophiles, animal abusers and rapists (Pendergrass and Wright, 2014), larger scale actions, like the ones against Scientology, shape the public image of Anonymous. The image as political actor for freedom of information took shape with Anonymous' support of WikiLeaks (Barnard-Wills, 2011; Beyer, 2014b; McCarthy, 2015) and the Arab Spring. With the engagement with the Occupy movement (Koch, 2014) the political agenda of Anonymous extended to include social justice. From 2011 on, Anonymous further diversified as it spread and developed collectives all over the globe, which often address national problems, like local corruption (e.g., Rone, 2014). Just as rational politics were an important part of Anonymous' early collective actions combining joyful pranks and schadenfreude with a rational strategy, so are lulz and the 
visual performance of power to generate fear an essential part of Anonymous' politics today. Emotions, passion and affect are not only evident in Anonymous' history, but also an elementary aspect of their organisational structure.

\section{Anonymous' politics of passion}

In order to understand the reconfiguration of reason/emotion in Anonymous, a broader look at the novel organisational forms of activism on the internet is necessary. New participatory constellations online are theorised in a growing literature on networks, swarms and clouds. McDonald (2015: 971) describes Anonymous in terms of Bennett and Segerberg's (2013) digital networked action, replacing hierarchical and inflexible social organisations, like unions with contingent online networks of individual activists. Wiedemann (2014: 317) and Deseriis (2013: 44) similarly explain Anonymous as a hybrid of network and swarm. While individuals and groups form nodes that are connected by stable communication channels, these individuals also engage in spontaneous leaderless swarms. Which form it takes mainly depends on the context: longer lasting campaigns need networked coordination, while ad hoc action erupts in swarms.

Milan describes Anonymous as cloud, not only to illustrate the mobility and contingency of the new collectivity, but also to refer to the cloud technology for knowledge formation and sharing (Milan, 2013b: 199). As costs for entrance and exit to the cloud are low, individuals frequently come and go (cf. Potter, 2015: 7). While they connect with one 
another, they are also free to pursue individual goals:

"The cloud, as an imagined space where meanings are created and reproduced, allows everyone to participate in building the collective plot. It gives voice and visibility to personalized yet universal narratives: the hashtag-style collective narrative is flexible, real-time, and crowd-controlled. It connects individual stories into a broader context that gives them meaning" (Milan, 2013b: 203).

Some claim participants lose their individual identity within Anonymous (Halpin, 2012: 22, cf. Cambre, 2014: 316; Coleman, 2012: 86; Koch, 2014: 465). Milan, however, argues that the collective inverted identity of Anonymous provides a frame for experiencing community and individuality at the same time (Milan, 2013b: 201).

Most other scholars in this field support Milan's identification of the technological context as a major explanatory factor for the novelty of participatory formations online. They unanimously point to the same two key features, distinguishing Anonymous from traditional social movements, both enabled by digital communication: the cooperation between spatially distant individuals and their anonymity, in contrast to face-to-face encounters (Fuchs, 2013: 347; McCarthy, 2015: 445; Wiedemann, 2014: 315). Describing Anonymous as e-bandits engaging in politics of no one, Wong and Brown (2013) state: 
"The critical component that distinguishes e-banditry from other social movements or even hacktivists is the disembodiment of activism. This decoupling of resistance and physical presence is central to the politics of no one, as technology enables anonymity that does not require individuals to physically gather for a show of strength or support" (p. 1022).

Cyborg theory, however, draws attention to the fact that disembodiment through technology is only one side of the coin. The other consists of two elements: first, the electronically mediated re-embodiment as digital persona, and second the actual material body of the activist, which - often forgotten in cyberutopian conceptions of a digital public sphere - still persists. Technology triggers and mediates emotion and is thus linked to the human body. "In order to capture the bodily affective qualities of the media infrastructure, digital objects such as the board 4chan must themselves be approached through the notion of affect [...] the abstractions that algorithmic measures are based on return to organic bodies as sounds and vision, as actions or frameworks for action" (Wiedemann, 2014: 316).

By fusing human and machine, cyborg activism reconfigures rational politics and emotion. The separation of these elements can be traced back in the history of Western thought to the separation of spirit and soul in early Christianity and is carried on today in the notion of rational deliberation. Deliberative democracy, arguably the most prominent concept in current democratic theory, is criticised by feminist thinkers for excluding 
emotion, affect and passion (Young, 2000). Some scholars of Anonymous argue that the introduction of emotion into politics is one core element that distinguishes Anonymous (Goode, 2015: 75). Halpin (2012: 23) describes Anonymous as Stimmung, the German word for "mood", closely related to the word voice (Stimme). Anonymous is interpreted as an emotional place, where individuals gather and jointly articulate their grievances, fears and hopes.

While the lulz have been rightly identified as the key concept for understanding Anonymous (Coleman, 2014), unfortunately they have often been referred to as proof for its apolitical nature, as discussed above. I would rather interpret lulz as the expression of a politics of passion. Here, reasoned politics and affective sentiments join:

"Many Anonymous actions seem to come about for a combination of political reasons, intimately connected with doing stuff (just), for the lulz'. For Anonymous, there is, hence, no opposition between the lulz and political engagement. The lulz can, as we suggest [...] also be understood as the (forbidden) pleasure or joy of fighting for something meaningful, the passion of (political) struggle [...] the lulz, translated into ,joy' (,joyful passions' or ,hope') are then basically fundamental for rebellion. Without joy, or the fantasy of hope, we cannot, imagine an ,alternative' to - and less revolting against - a given political situation" (Ferrada Stoehrel and Lindgren, 2014: 257f). 
What is described here in positive terms can be extended to negative aspects as well. New communication technologies not only provide for the expression of joy and a passionate progressive rebellion but also invoke fear and cause insult. The aesthetic performance of Anonymous is characterised by sinister and dark visuals and sounds, employed in an attempt to create a powerful and threatening collective identity as expressed in their mantra: "We are Anonymous. We are legion. We do not forgive. We do not forget. Expect us." Thus, Anonymous' anger towards its political opponents has led to the reasoned strategy of evoking fear.

This illustrates how cyborg activists use the possibilities of developing new digital personae for political purposes. The reconfiguration of identity/anonymity enables cyborg activists to appear under multiple frames as heroes, vigilantes, party supporters, guerrilla fighters or protesters. Anonymous' Guy Fawkes mask creates a digital persona with clear political implications: Guy Fawkes unsuccessfully executed the Gunpowder Plot of 1605 on the British parliament. The current graphic version of the mask was developed in the 1980s worn by the comic Anarchist hero V who fights fascist dictatorship. Anonymous thus performs an Anarchist super hero/guerilla fighter to counter the corrupt entanglement of economic and political elites (Cambre 2014; Koch 2014). Simultaneously, with the mask Anonymous also performs anonymity, the opposite of identity. Thus the mask can be read as rebellion against identification and data collection (McDonald, 2015: 979). Both identity change and doing away with identity 
needs to be understood in the context of a politics of passion. It is an act of empowerment of "the nerds" who, as victims of social ostracism, use means of digital communication to transform into a sinister and vengeful hero and at the same time rebel against the existence of social hierarchies.

\section{The reconfiguration of nihilism/idealism in Anonymous}

The analyses of Anonymous' political claims and promoted contents draw attention to the reconfiguration of a third binary. While some authors locate Anonymous in the realm of nihilism as a result of its inconsistency and lack of ideology, others identify coherent ideological patterns. As Goode (2015) points out, paradoxically Anonymous proves to be both, nihilist and idealist. Both the assumption of nihilism and idealism reflects a diversity of ideas, which is symptomatic of cyborg activism and is also accounted for in Bennett and Segerberg's (2013) connective action. The reconfiguration of nihilism/idealism reflects elements of the two binaries discussed above: While nihilism is often connoted with irrationality and emotion, idealism is associated with enlightened reason. In the diversity of Anonymous content both egalitarian and hierarchical thought can be identified.

\section{Of nihilist idealism}

Scholars are divided on whether Anonymous is to be perceived as idealist as comprehensible ideological patterns can be identified (Barnard-Wills, 2011: 21; Hai- 
Jew, 2013) or as nihilist for its inconsistency of political claims (Coleman, 2013: 3; 2012: 84; McCarthy, 2015: 440; Uitmark, 2016: 1). “Anonymous demonstrates how the common cannot take on an ethical or coherent political message. It can only produce a heterogeneity of spontaneous actions, contradictory messages, and embrace its contradictions, its act of vigilant justice as much as its dark, racist, sexist, homophobic and predatory qualities" (Ravetto-Biagioli, 2013: 187). Results of Klein's (2015: 13) content analysis draw a different picture. The study identifies three political - or idealist, for that matter - motivations in the statements of Anonymous published via social media: Free speech accounts for $41 \%$, social justice for another $41 \%$ and antisurveillance for $13 \%$. Only for $5 \%$ of the actions could no political motivation be identified.

While Klein identifies free speech and social justice as a clear idealist agenda of Anonymous, Goode (2015: 79-81) draws attention to the nihilist attitudes in Anonymous that go along with its idealism. This nihilism, however, should not be interpreted as apolitical, rather it contains in itself normative elements which results in a reconfigured nihilist idealism. Both Goode and Coleman (2014: 399) explain Anonymous' nihilism as an outlet for frustration with the seeming lack of alternatives in today's politics - a reasoned emotional reaction resulting in nihilist attitudes and idealist claims. In other words, Anonymous' idealist agenda is framed in nihilist terms and performances. 
Cambre (2014) states: "It is needless to note the non-having of an ideology is itself an ideology. Claiming such may also be a mask" (p. 304). So even where no idealist agenda is identifiable within Anonymous, the performance of anonymity alone can be interpreted as political and normative content (Coleman 2011b: 513; Wesch, 2012: 94). On the one hand, anonymity facilitates nihilist, selfish action, and on the other, it promotes idealist equality and meritocracy. Moreover, the visual performance of anonymity online can be read as a protest against identification and data collection (Cambre, 2014: 305; McDonald 2015: 979; Wesch, 2012; 96). So Anonymous' nihilism may well contain implicit political claims as part of an idealist agenda.

\section{The many meanings of Anonymous}

Both nihilist and idealist tendencies in Anonymous testify to a great diversity of ideas. While accounts of nihilism hint at such a wide range of topics and claims that no coherent ideology can be identified, most accounts of ideological patterns in anonymous also stress a heterogeneity of content. Attempts to systematise political claims promoted in the many manifestos, video messages and visual performances of Anonymous once again rely on binaries. Content is analysed in a spectrum between liberalism vs. socialism and representative vs. direct democracy hinting at novel configuration and integrations of a diversity of ideas.

Some scholarly accounts clearly place Anonymous at one respective end of the liberal vs. socialist continuum. Analysing the targets attacked by Anonymous, Hai-Jew (2013) 
concludes that Anonymous' goal is "to abolish authoritarian institutions that control various means of production and subordinate the majority to the property-owning class" (p. 74; cf. Deseriis, 2013). She describes Anonymous' utopia of complete transparency: "Without the hierarchies of information, people would theoretically be classless" (HaiJew, 2013: 74). On the contrary, results from a frame analysis of video messages and public statements of Anonymous lead McCarthy (2015: 448) to locate Anonymous' claims in a liberal human rights discourse. Similarly, Barnard-Wills (2011) states: "[The values] of transparency, institutional accountability and freedom of speech [...] put forward by Anonymous are not extrinsic to liberal theory" (p. 21).

Others arrive at mixed conclusions. Klein's (2015: 13) content analysis cited above identifies two major political motivations in the statements of Anonymous published via social media: Free speech, which can be identified as liberal core value, accounts for $41 \%$ and social justice, which can be identified as socialist core value, for another $41 \%$. Similarly, Goode (2015: 83) shows that both negative freedoms, a liberal notion addressing protection from state interference in the private sphere, and positive freedoms, a socialist notion addressing the state's responsibility to provide basic goods to citizens, are evident in Anonymous' ideas. More detailed results are generated in an extensive study by Fuchs (2013), consisting of a qualitative discourse and quantitative content analysis of 67 video messages of Anonymous. The content analysis shows that $55 \%$ of the messages contain only liberal, $8 \%$ only socialist and $22 \%$ both viewpoints. While in 
their pure form, liberal values dominate over socialist values, the big overlap is telling. Accordingly, the discourse analysis detects both right-wing cyberlibertarian and left-wing cybersocialist ideas. The dominant ideology within Anonymous, however, is characterised by a new brand of social cyberlibertarianism, fusing socialist and liberal thought. Freedom is the main motive, under which both negative and positive freedoms are subsumed. "On the one hand, [Anonymous] to a certain extent affirms liberal values; on the other hand it constitutes an immanent critique of these values by showing how liberal institutions violate the liberal values of the system that they represent" (Fuchs, 2014: 102; cf. Coleman, 2011b: 513).

This dichotomous thought of liberalism and socialism within Anonymous also plays into discussions about participatory democracy and representative democracy. Once again, scholars appear divided. Some see Anonymous "in support of a somewhat fuzzy notion of popular democracy" (Halpin, 2012: 25). Fuchs (2013) identifies "the call for the creation of a just and equal participatory democracy" (p. 370) as part of socialist ideological elements. And Rone (2014: 720) summarises Anonymous' Bulgaria's alternative vision as direct, digital democracy. Others, however, observe Anonymous' democratic vision as framed in representative democratic terms (Barnard-Wills, 2011: 21; Beyer, 2014b: 27; McCarthy, 2015; 448). "[Anonymous'] emphasis on the protection of citizens from a powerful state represents the ideal of negative rights, characteristic for the U.S.-American model of liberal democracy" (Koch, 2014: 463). 
The shifting binaries liberalism/socialism and representative/participatory democracy render new configurations on the level of content. Of course, libertarian thought located between liberalism and socialism as such is not new. The novelty, however, derives on the one hand from the new electronic medium and the possibilities thereof resulting in cyberlibertarian thought as promoted by other groups in the hacktivist and open source movement. on the other hand the novelty derives from an openness exceeding cyberlibertarianism, which is partly enabled by its nihilist framing: Paradoxically the denial of content opens the door for a greater diversity of content resulting in the inclusion of both racist and humanist, feminist and misogynist, egalitarian and meritocratic thought.

\section{Conclusion}

In order to make sense of new forms of political activism on the internet, this article developed the concept of cyborg activism. Discussions of new forms of political activism on the internet like Castells'(2012) networked social movements and Bennett and Segerberg's (2013) connective action have drawn attention to important features of digital activism like (1) new horizontal modes of decision making, (2) emotive interaction, and

(3) diverse content. Here these insights are expanded by understanding the activist as cyborg reconfiguring modern binaries. Cyborg activism shifts the focus to (1) both horizontal and hierarchical forms of decision making (cf. Gerbaudo 2012), (2) emotive and reasoned interaction, and (3) nihilist and idealist tendencies resulting in diverse contents. Aiming at disrupting the modern logic behind common conceptualisations of 
social movements, the concept of cyborg activism avoids one-sidedness (cyberoptimism/pessimism) through its binary focus.

1. The case of Anonymous illustrates that cyborg activist formations are not merely characterised by new equality and horizontal means of communication as in Castells' networked social movements and Bennett and Segerberg's connective action. Rather as in Gerbaudo's choreographic leadership, leadership keeps emerging, shifting, and expiring. Leaders suggest action and depend on a critical mass of activists to support it. The study of Anonymous demonstrates that the structural settings of different interfaces have a great effect on power relations. In completely anonymous settings, leaders hardly emerge at all; in pseudonymous settings with nicknames as identification markers, leadership may expire more frequently compared to offline settings as nicknames might be changed and costs of exit are lower. Moreover, the examination of 4chan as the place of emergence of Anonymous illustrated the ambiguous effects of anonymity: On the one hand anonymity conceals identity markers tied to social hierarchies in face-to-face settings, thus contributing to equality, meritocracy, and inclusion. On the other hand, anonymity triggers hierarchizing effects as disinhibition leads to verbal insults and exclusion of marginalised social groups. The paradox, however, is even more complicated. Insults not only serve to exclude but also build solidarity as derogatory terms 
become self-ascriptions and terms of endearment.

2. Like in Castells' and Gerbaudo's conceptualisations of digital activism, emotive elements play a crucial role in Anonymous. Cyborg activism draws attention to reasoned or strategic responses to emotional triggers and the non-exclusivity of the respective realms of emotion and reason, which are oddly intertwined by technological mediation. New means of communication mediate formerly private emotions into the public sphere. Outrage at child molesters, animal abusers or even large scale corporations can now be directly addressed. In the case of Anonymous, this facilitates the trolling of political opponents. Along with the new proximity also goes new distance. Once more paradoxical, people are more easily accessible for communication but at the same time remain strangers, which decreases the inhibition to inflict harm. Political trolling is, however, only one component of the new politics of passion. The strong experience of community, for example the rush of a commonly organised DDoS attack or the participation in a raid on Habbo Hotel, while physically being in solitude, is another phenomenon bringing new qualities to activism.

3. Castells describing networked social movements as non-programmatic or Bennett and Segerberg explaining action frames as inclusive and individualising might give the impression that digital activists do not have a political agenda or ideological convictions. Cyborg activism draws attention to the interrelation of 
nihilist disenchantment with politics and idealist political convictions. Anonymous demonstrates how the performance of disenchantment with politics and the denial of political content can contain substantial political messages. Moreover, this opens up space for a diversity of idealist convictions and makes the cohabitation and partial fusion of various political claims possible.

The exploration of Anonymous has shed light on the concrete workings of cyborg activism. Other examples and empirical work might bring new insights or expand the concept. What can cyborg activism tell us about the Occupy movement, the Zapatistas or groups like WikiLeaks and Pirate Parties? How do they renegotiate equality/hierarchy through online communication? How are emotions expressed and how are they relate to reasoned politics? What ideological fusions and nihilist attitudes are observable? Activism and online engagement in the context of rapid global change is a fast emerging field of study. This article presented an attempt to disrupt traditional ways of thinking as I am convinced that it is necessary to develop new perspectives for new phenomena, which at the same time, however, do not completely break with the past, but pay attention to both continuity and novelty.

\section{References}

Barnard-Wills D (2011) 'This is not a cyber war, it's a...?' International Journal of Cyber 
Warfare and Terrorism 1(1): 13-23.

Bennett WL and Segerberg A (2013) The Logic of Connective Action: Digital Media and the Personalization of Contentious Politics. Cambridge: Cambridge University Press.

Beyer J (2014a) Expect Us: Online Communities and Political Mobilization. Oxford: Oxford University Press.

Beyer J (2014b) The Emergence of a Freedom of Information Movement: Anonymous, WikiLeaks, the Pirate Party, and Iceland. Journal of Computer-Mediated Communication 19: 141-154.

Bodó B (2014) Hacktivism 1-2-3: how privacy enhancing technologies change the face of anonymous hacktivism. Internet Policy Review 3(4): 1-13.

Cambre M-C (2014) Becoming Anonymous: A Politics of Masking. In: Venkatesh V, Wallin J, Castro JC et al. (eds) Educational, Psychological, and Behavioral Considerations in Niche Online Communities. Hershey: Information Science Reference, pp. 297-321.

Castells, Manuel (2012) Networks of Outrage and Hope: Social Movements in the Internet Age. Cambridge: Polity.

Coleman G (2011a) Anonymous: From the Lulz to collective action. The new everyday: A media commons project. Available from http://mediacommons.futureofthebook.org/tne/pieces/anonymous-lulz-collective-action. 
Coleman G (2011b) Hacker Politics and Publics. Public Culture 23(3): 511-516.

Coleman G (2012) Our Weirdness Is Free. May 6: 83-111.

Coleman G (2013) Anonymous in Context: The Politics and Power behind the Mask. Internet Governance Papers 3: 2-23.

Coleman G (2014) Hacker, hoaxer, whistleblower, spy: The many faces of Anonymous. London: Verso.

Deseriis M (2013) Is Anonymous a New Form of Luddism? A Comparative Analysis of Industrial Machine Breaking, Computer Hacking, and Related Rhetorical Strategies. Radical History Review 117: 33-48.

Dobusch L and Schoeneborn D (2015) Fluidity, Identity, and Organizationality: The Communicative Constitution of Anonymous. Journal of Management Studies 1-31.

Dunn Cavelty M and Jaeger MD (2015) (In)visible Ghosts in the Machine and the Powers that Bind: The Relational Securitization of Anonymous. International Political Sociology 9(2): 176-194.

Ferrada Stoehrel R and Lindgren S (2014) For the Lulz: Anonymous, Aesthetics and Affect. tripleC: Communication, Capitalism \& Critique. Journal for a Global Sustainable Information Society 238-264.

Fish A (2015) Mirroring the Videos of Anonymous: Cloud Activism, Living Networks, 
and Political Mimesis. The Fibreculture Journal (26): 85-107.

Fuchs C (2013) The Anonymous movement in the context of liberalism and socialism. Interface: A journal for and about social movements 5(2): 345-376.

Fuchs C (2014) Anonymous: Hacktivism and Contemporary Politics. In: Trottier D and Fuchs C (eds) Social Media, Politics and the State. New York: Routledge, p. 88-106.

Gekker A (2012) Legionnaires of Chaos: ‘Anonymous' and Governmental Oversight of the Internet. In: Heider D and Massanari R (eds) Digital Ethics: Research and Practice. New York: Peter Lang Publishing, pp. 178-192.

Gerbaudo P (2012) Tweets and the Streets: Social Media and Contemporary Activism. New York: Pluto Press.

Goode L (2015) Anonymous and the Political Ethos of Hacktivism. Popular Communication: The International Journal of Media and Culture 13(1): 74-86.

Hai-Jew S (2013) Action Potentials: Extrapolating an Ideology from the Anonymous Hacker Socio-Political Movement (A Qualitative Meta-Analysis). In: Akrivopoulou C, Johnston L and Wolfe K (eds) Digital Democracy and the Impact of Technology on Governance and Politics: New Globalized Practices. Hershey: Information Science Reference, pp. 51-107.

Halpin H (2012) The philosophy of Anonymous: Ontological politics without identity. 
Radical Philosophy 176: 19-28.

Halupka M and Star C (2011) The Utilisation of Direct Democracy and Meritocracy in the Decision Making Process of the Decentralised Virtual Community Anonymous. In: The Australian Political Studies Association Conference Proceedings 12.

Jarvis JL (2014) Digital image politics: The networked rhetoric of Anonymous. Global Discourse: An Interdisciplinary Journal of Current Affairs and Applied Contemporary Thought Publication 4(2-3): 1-24.

Kafai YB, Fields D, and Cook MS (2007) Your Second Selves: Resources, Agency, and Constraints in Avatar Designs and Identity Play in a Tween Virtual World. In: Situated Play, Proceedings of DiGRA 2007 Conference, pp. 31-39.

Kelly BB (2012) Investigating in a Centralized Cybersecurity Infrastructure: Why 'Hacktivism' can and should Influence Cybersecurity Reform. Boston University Law Review 92(5): 1663-1711.

Klein AG (2015) Vigilante Media: Unveiling Anonymous and the Hacktivist Persona in the Global Press. Communication Monographs 82(3): 1-23.

Koch CM (2014) Occupy Popular Culture: Anonymous, Occupy Wall Street, and the Guy Fawkes Mask as a Political Icon. In: REAL- Yearbook of Research in English and American Literature 30. Tübingen: Gunter Narr. 
Krauth A (2012) Anonymous in Portmanteaupia. Social Alternatives 31(2): 27-32.

Mansfield-Devine S (2011) Anonymous: Serious threat or mere annoyance? Network Security: 1, 4-10.

McCarthy MT (2015) Toward a Free Information Movement. Sociological Forum 30(2): 439-458.

McDonald K (2015) From Indymedia to Anonymous: Rethinking action and identity in digital cultures. Information, Communication \& Society 18(8): 968-982.

Milan S (2013a) Social Movements and Their Technologies: Wiring Social Change.

Houndmills: Palgrave Macmillan.

Milan S (2013b) WikiLeaks, Anonymous, and the Exercise of Individuality: Protesting in the Cloud. In: Brevini B, Hintz A and McCurdy P (eds) Beyond WikiLeaks: Implications for the Future of Communications, Journalism and Society. Houndmills: Palgrave Macmillan, pp. 191-208.

Padmanabhan S (2012) Hacking for Lulz: Employing Expert Hackers to Combat Cyber Terrorism. Vanderbilt Journal of Entertainment and Technology Law 15(1): 191-226.

Pendergrass WS and Wright M (2014) A Case Study Analysis of KnightSec and the Steubenville Rape Case. In: Proceedings of the Conference for Information Systems Applied Research. Baltimore, pp. 1-11. 
Phillips W (2012) The House That Fox Built: Anonymous, Spectacle, and Cycles of Amplification. Television \& New Media 14(6): 494-509.

Potter G (2015) Anonymous: A Political Ontology of Hope. Theory in Action 8(1): 1-23.

Pras A et al. (2010) Attacks by 'Anonymous' WikiLeaks Proponents not Anonymous. CIT Technical Report 10.41: 1-10.

Ravetto-Biagioli K (2013) Anonymous: Social as political. Leonardo Electronic Almanac 19:(4): 178-195.

Rone J (2013) Anonymous Bulgaria: «I like to lumpen lumpen». In: Internet, Law \& Politics. A Decade of Transformations, Proceedings of the 10th International Conference on Internet, Law \& Politics., pp. 709-725.

Sauter M (2013) 'LOIC Will Tear Us Apart': The Impact of Tool Design and Media Portrayals in the Success of Activist DDOS Attacks. American Behavioral Scientist 57(7): 983-1007.

Sauter M (2014) The Coming Swarm: DDOS Actions, Hacktivism, and Civil Disobedience on the Internet. New York: Bloomsbury.

Serracino-Inglott P (2013) Is it OK to be away? Ethics \& Global Politics 6(4): 217-244.

Uitermark J (2016) Complex Contention: Analyzing Power Dynamics within Anonymous. Social Movement Studies 1-15. 
Vivienne S and Burgess J (2012) The Digital Storyteller's Stage: Queer Everyday Activists Negotiating Privacy and Publicness. Journal of Broadcasting \& Electronic Media 56(3): 362-377.

Wesch M and the Digital Ethnography Class 2009 (2012) Anonymous, Anonymity, and the End(s) of Identity and Groups Online: Lessons from the 'First Internet-Based Superconsciousness'. In: Whitehead NL and Wesch M (eds) Human No More: Digital Subjectivities, Unhuman Subjects, and the End of Anthropology. Colorado: University Press of Colorado, pp. 89-104.

Wiedemann C (2014) Between swarm, network, and multitude: Anonymous and the infrastructures of the common. Distinktion: Scandinavian Journal of Social Theory 15(3): $309-326$.

Wong WH and Brown PA (2013) E-Bandits in Global Activism: WikiLeaks, Anonymous, and the Politics of No One. Perspectives on Politics 11(04): 1015-1033. Young IM (2000) Inclusion and Democracy. Oxford: Oxford University Press.

Zhao S, Grasmuck S, and Martin J (2008) Identity Construction on Facebook: Digital Empowerment in Anchored Relationships. Computers in Human Behavior 24(5): 18161836. 


\footnotetext{
${ }^{1}$ The number in brackets indicates the number of sources used in this literature review.

${ }^{2} \mathrm{~A}$ meme is a repeated and sometimes modified (and thus re-interpreted) articulation, like a visual or a sentence that is spread within a social network.

${ }^{3}$ Internet lingo for a plural version of "laughing out loud", lol.
} 